\title{
Lokalno upravljanje in novi javni menedžment
}

UDK: 352:005

\author{
Irena Bačlija
}

Univerza v Liubljani, Fakulteta za družbene vede

irena.baclija@fdv.uni-li.si

\section{IZVLEČEK}

Ekonomska globalizacija, vedno boli diferencirani in nestabilni trgi, fiskalne krize $v$ luči vse večje javne porabe so elementi negotove prihodnosti za lokalne skupnosti. Slednje so ujete med vedno večje povpraševanje uporabnikov oziroma občanov po kakovostnih javnih storitvah ter regulativo države, ki (lahko) duši kreativni razvoj in tekmovanje na globalnem trgu lokalnih skupnosti. V tem kontekstu vedno zahtevnejšega okolja deluje tudi lokalna uprava, ki se mora za uspešno soočenje s prvinami tega okolja reformirati. $V$ prispevku poleg značilnosti lokalnega upravljanja predstavimo tudi njegovo reformiranje po načelih novega javnega menedžmenta. $V$ empiričnem delu predstavimo izsledke obsežnejše študije reformiranja lokalnih uprav v Evropski uniji ter implikacije, ki jih ima delovanje reformiranih lokalnih uprav na uspešnost celotne lokalne skupnosti.

Ključne besede: lokalno upravljanje, novi javni menedžment, lokalne skupnosti

JEL: $D 73$

\section{Uvod}

Ekonomska globalizacija, vedno boli diferencirani in nestabilni trgi, fiskalne krize $v$ luči vse večje javne porabe so elementi negotove prihodnosti za lokalne skupnosti. ${ }^{1}$ Nekatere lokalne skupnosti so se

$1 \mathrm{~V}$ svojem bistvu lokalna skupnost označuje teritorialno skupnost ljudi, ki svoje skupne potrebe zadovoljujejo s skupnimi dejavnostmi. Pravnosistemsko institucijo, ki opredeljuje status lokalne skupnosti, imenujemo lokalna samouprava. Analitično gledano združuje torej pojem lokalne samouprave dve sestavini: lokalno skupnost kot sociološko sestavino in lokalno samoupravo kot pravnosistemsko sestavino. Samoupravnost mora biti izrecno podeljena oziroma priznana lokalni skupnosti s strani države. Kot taka ima nekaj

Bačlija, I. (2011). Lokalno upravljanje in novi javni menedžment.

Uprava IX(4), 97-115. 
ohranile kot lokalne družbe, druge so izgubile svojo strukturo in so bile daljše obdobje podrejene nacionalnim in mednarodnim strategijam. Vsekakor se morajo lokalne skupnosti prilagoditi novonastalim razmeram bodisi z inovacijami $v$ delovanju oziroma upravljanju bodisi z uvajanjem uspešnih praks drugih skupnosti. Strategija posnemanja uspešnih javnih politik in programov ima korenine $v$ spremembi razvojne paradigme $\vee 70$. in 80. letih (Harvey, 1989; Keating, 1998; Brenner, 1999). Pred tem sta bila $v$ veljavi le dva izrazita tipa vladne funkcije - proizvodnja in potrošnja. Nacionalna raven je imela funkcijo proizvodnje, lokalne skupnosti pa so skrbele za potrošnjo, s čimer so zagotavljale stalno delovno silo (O'Connor, 1973; Saunders, 1986; Harvey, 1989; Harding, 2005). Vplivi globalizacije so povzročili vedno večjo proaktivno vlogo lokalnih skupnosti, ki so začele načrtovati lasten razvoj. Lokalne oblasti, celo tiste iz različnih družbeno-političnih okolij, so se srečale z enakim izzivom ekonomskega razvoja, na katerega so odgovarjale s podobnimi inovativnimi politikami (Mayer, 1995; Porter, 1998; Harding, 2005).

Bramezza (1996) meni, da je odziv lokalnih skupnosti na globalne vplive sicer lahko različen glede na predispozicije (zgodovinske, zakonodajne, makroekonomske) in okolje (politično, ekonomsko, upravo), vendar obstaja način upravljanja, ki omogoča optimalno izrabo potenciala predispozicii in okolja. Tako menita tudi Pollitt in Bouckaert (2004, str. 8), ki pravita, da se da glede na zunajsistemske vplive, ki so botrovali reformiranju javnega sektoria, zaključiti, da je reformiranje istovrstnih organizacii (organizacii lokalne uprave) potekalo po enakih principih. Prevladujoči princip modernizacije lokalnega upravljanja ko† odziv na globalne spremembe je implementacija koncepta(ov) novega javnega menedžmenta (NJM). Načela in orodja NJM so namreč v široki uporabi na lokalni ravni. Daeman in Schaap (2000, str. 175) na podlagi empirične raziskave dodatno dokazujeta, da so orodja NJM na lokalni ravni $\vee$ Evropi $\vee$ splošni uporabi, podobno je tudi $\vee$ mestih $\vee$ ZDA (New York (Weikart, 2001), Milwaukee (Norquist, 1998) in Indianapolis (Goldsmith, 1998)) ter drugod po svetu (Prohl, 1997).

$\checkmark$ članku želimo prikazati dve osredni točki. Prvič, da je lokalno upravljanje $\vee$ postweberjanskem času posebnega pomena, saj se vedno

značilnosti, po katerih se ločuje od državne uprave. To so po Vlaju (1992) avtonomija, samostojnost, decentralizacija in demokratizacija, ki dajejo lokalnim skupnostim pravico, da urejajo in opravljajo v svoji pristojnosti javne zadeve, ki se nanašajo na življenje in delo prebivalcev na njihovem območju. 
več nalog prenaša na lokalno raven, ki se mora poleg povečanja obsega dela soočati tudi s tekmovanjem za finančne resurse in nastopanjem na globalnem trgu lokalnih skupnosti. $V$ tem kontekstu vedno zahtevnejšega okolja deluje tudi lokalna uprava, ki se mora za uspešno soočenje s prvinami tega okolja reformirati. In drugič, želimo z rezultati študije modernizacije lokalnih uprav na primeru 58 mest $v$ Evropski uniji (EU) prikazati realne posledice modernizacije lokalne uprave za lokalno skupnost. Dosedanje (sicer redke) raziskave modernizacije lokalnih uprav po vzoru NJM (Hambleton, 2004; Daeman in Schaap, 2000; Weikart, 2001; Norquist, 1998; Goldsmith, 1998; Prohl, 1997) so pokazale, da se reforme izvajajo, vendar niso odgovorile na ključno vprašanje - ali ima reformirano upravljanje dejanski vpliv na celotno lokalno skupnost. V okviru tega $v$ zaključnem delu članka prikazujemo statistične povezave med indeksom NJM ter a) številom prebivalcev $v$ lokalni skupnosti, b) povprečnim BDP-jem $\vee$ lokalni skupnosti, c) indeksom moči ter d) lizbonskim benchmarkom. Nakazane povezave nam namreč lahko ponudijo odgovor na realne implikacije reformiranja lokalnih uprav ter $\mathrm{s}$ tem boli oprijemljiv argument za nadalinie tovrstne procese.

\section{Globalni vplivi na lokalno upravljanje}

Upravljanje na lokalni ravni se $v$ marsičem razlikuje od upravljanja na splošno (tukaj mislimo predvsem na upravljanje na nacionalni ravni in ne toliko na upravljanje $v$ zasebnem sektorju). Razlogov za to je več. Lokalna uprava in lokalna oblast sta bližje uporabniku (občanu), zato sta lahko boli odzivni in boli prilagodljivi. Po drugi strani so lokalne oblasti v veliki meri omejene z nacionalnimi zakonodajnimi okviri, ki (lahko) dušijo razvoi in kreativnost vodenja in upravljanja ter s tem uspešnost posamezne lokalne skupnosti. Tako mora biti lokalno upravljanje še toliko bolj iznajdliivo in kreativno, da po eni strani odgovori na neposredne pritiske občanov ter uspešno "krmari" znotraj omejitev, ki jih zadaja država. Vsekakor na lokalno upravljanje poleg push-pull efekta, ki ga ustvarjajo občani in državna regulativa, vplivajo tudi globalni trendi. Slednje bomo v članku predstavili v okviru treh globalnih gibanj/pojavov: globalizacije, neoliberalizma in vala decentralizacije. Našteti pojmi se $v$ določenih točkah prekrivajo. Tako je pogosto nejasno, kaj je posledica neoliberalizma in kaj globalizacije. Upoštevati pa je na primer treba tudi, da NJM, ki je posledica neoliberalizma, vključuje decentralizacijo kot tako. 
Pri globalizaciji gre za pritiske globalnih korporativnih elit na zmanjševanje vloge socialne države oziroma za zmanjševanje vloge države nasploh (Habermas, 1991; Offe, 1985). Nekateri menijo, da so zaradi neodvisnosti multinacionalnih korporacii od katerekoli nacionalne države le-te postale nepomembne ali celo odvečne (Ball, 1967; Naisbitt, 1994). Za Steverja (1988) pomeni globalizacija konec javnega sektorja, za Rifkina (1996) pa celo konec dela. Po drugi strani Brezovšek in Črnčec (2007, str. 28) ugotavljata, da globalizacija ni povzročila konca države in njene uprave (birokracije) in da se to $v$ bližnji prihodnosti ne bo zgodilo, saj so odnosi med trgom in politiko, kapitalizmom in državo, zasebnim in javnim sektorjem notranje soodvisni. Globalizacijski tokovi vplivajo tudi na upravne sisteme posameznih držav, ki so okrepljeni z možnostmi informacijske tehnologije in zahtevami po večji učinkovitosti. Vsi ti pritiski delujejo na strukturo upravnih sistemov, na njihovo avtonomijo in metode upravljanja $\vee$ njih ter na njihov obseg. Zahtevajo bodisi večjo centralizacijo, da bi se država lažje vklopila $\vee$ nadnacionalne upravne mreže, bodisi večjo decentralizacijo, da bi se v globalno akcijo vključili tudi nedržavni akterii. Korten (1995) meni, da globalizacija ogroža lokalne skupnosti, saj zmanjšuje lokalni nadzor in relevantnost lokalne participacije (in s tem tudi demokracije). S tem zmanjšuje vlogo občanov, pa tudi lokalnih javnih uslužbencev na sprejemanje odločitev, ki so pomembne za lokalno okolje (Farazamand v Bevir, 2007). Z umikanjem ali preselitvijo proizvodnje ali svojih sedežev lahko multinacionalke ogrozijo finančno vzdržnost lokalnega proračuna. Naloga lokalne uprave je, da s sklepanjem dolgoročnih partnerstev z multinacionalimi vlagatelji zmanjša to finančno negotovost.

Neoliberalistična reforma javnega sektorja izhaja iz 70 . let, njen prvi val pa se je manifestiral $\vee$ NJM. Z zmanjševanjem vloge uprave in vstopom nekaterih zasebnih podjetij v proces zagotavljanja javnih storitev naj bi bile storitve učinkovitejše in ekonomska rast večja. Na osnovi ekonomskih neoklasičnih pristopov se je leta 1980 sprožil val reform, ki so poskušale nove ekonomske teorije in spoznanja vnesti $v$ delovanje javnih uprav (Hughes, 2003). Spremembe, ki jih je neoliberalizem povzročil za lokalne skupnosti, so po Breneriu in Theodoru (2002) zmanjševanje državne finančne podpore za zagotavljanje javnih storitev, devolucija novih nalog in obremenitev ter oblikovanje mehanizmov nagrajevanja in sofinanciranja podjetniškega vedenja lokalnih skupnosti. Poleg tega pa tudi odmik od birokratsko organizirane lokalne uprave ter 
prehod $k$ privatizaciji javnih storitev, ustvarjanju javno-zasebnih partnerstev ter delovanje po principu NJM. Neoliberalizem je spodbudil oblikovanje novih institucionalnih obvodov, skozi katere lahko ekonomske elite neposredno vplivajo na pomembnejše razvojne odločitve. Ustvarjajo se posebne podjetniške cone (na primer tehnološki parki), zmanjšujejo se davki za vlagatelie, poudarjena je funkcija nastopanja na globalnem trgu lokalnih skupnosti.

Obenem ima na lokalno upravljanje vpliv tudi decentralizacija (prenos pristojnosti z nacionalne na lokalne ravni). Nekateri avtorii vidijo decentralizacijo kot nujen korak k večji demokratizaciii (Diamond, 1999; Huther \& Shah, 1998; Fox, 1994), za druge pa je to način učinkovitejšega in uspešnejšega zagotavljanja javnih storitev (začne že Tiebout, 1956; kasneje Prud'homme, 1995; Stein, 1998; Tanzi, 1994). Kroukamp in Lues (2000) menita, da so val decentralizacije povzročili modernizacija nacionalne uprave, demokratizacija in ekonomski pritiski, ki so zahtevali čim bolj učinkovito zagotavljanje javnih storitev. Zaradi pritiskov neoliberalizma, ki je zahteval čim bolj vitko državo, se je velik del storitev prenesel na pleča lokalnih oblasti. Pristop k decentralizaciji je (bil) $\checkmark$ posamezni državi različen in pogojen z okoliščinami (institucionalni okvir, ekonomska stabilnost, zgodovinske izkušnje, civilno-družbene potrebe in podobno), izkušnje zadnjih dveh desetletii pa kažejo, da se posamezni principi decentralizacije uporabljajo $v$ skoraj vseh državah po svetu (Dillinger \& Fay, 1999).

\subsection{Zagotavljanje javnih storitve - prevladujoča funkcija lokalnih skupnosti}

Zagotavljanje javnih storitev na lokalni ravni izhaja iz procesa decentralizacije. Decentralizacija prenaša izvajanje javnih storitev po načelu subsidiarnosti na najnižjo možno lokalno raven, ki je še zmožna kakovostno zagotavljati določeno javno storitev. Takšno razumevanje določanja pristojnosti prinaša tri glavne prednosti. Prvič, lokalna oblast je najbližja prebivalcem, zato najbolje razume in prepozna niihove potrebe, poleg tega pa ima legitimnost za takšno početje. Drugič, fleksibilnost lokalnega političnega odločanja omogoča prilagajanje lokalnim razmeram in spremembam pri povpraševanju po javnih storitvah. Ne nazadnje pa je prednost tudi učinkovitost pri zagotavljanju javnih storitev, ki nastaja zaradi politične odgovornosti lokalnih oblasti. 
Z valom decentralizacije $\vee$ 80. letih se je levji delež izvajanja javnih storitev prenesel na lokalno raven. Sicer so postopoma, od 19. stoletja dalje, lokalne oblasti vedno boli prevzemale operativne funkcije za zagotavljanje javnih storitev kot so vodovod, kanalizacija, oskrba s plinom in podobno, kar je kasneje vodilo v razširjen nabor javnih storitev, ki naj bi jih lokalne skupnosti zagotavljale (to so zdravstvo, šolstvo, javni prevoz in podobno) (ECOTEC, 2007). Preskok pri prenosu dodatnih pristojnosti na lokalne skupnosti je potekal kot posledica treh sprememb $v$ družbi. Pred letom 1945 je bil obseg lokalnih storitev, kljub pestrosti lokalnih struktur in režimov $v$ Evropi, precej podoben. S pojavom socialne države in kolektivizma se je ta slika po letu 1945 precej spremenila, sai so nacionalne vlade vzhodno- in srednjeevropskih držav prevzele $v$ svojo pristojnost izvajanje mnogih javnih storitev. Naslednji večji izziv za servisno funkcijo lokalnih skupnosti je bil pojav neoliberalizma in paradigme NJM sredi 80 . let. Z uvajanjem nove ekonomske in družbene doktrine se je pojavil val privatizacije javnih servisov in služb (posebej očiten je primer Velike Britanije), kar je ponovno vodilo $v$ erozijo servisne funkcije lokalnih skupnosti. Zadnja vidnejša sprememba, ki je botrovala prenosu pristojnosti, pa je reforma lokalne samouprave $\vee$ vzhodnih in srednjeevropskih državah po letu 1989, ko so lokalne skupnosti dobile dejanske pristojnosti za izvajanje javnih storitev. Pred tem so bile samo izvajalke direktiv nacionalnih vlad (ibidem).

\section{Reformiranje upravljanja - NJM}

Lokalno upravljanje je zaradi že omenjenih pritiskov na lokalne skupnosti (vedno več nalog prenesenih nalog ter tekmovanje za finančne resurse - tako od države kot od vlagateljev) tisti element, s pomočjo katerega neka skupnost lahko uspešno zagotavlja javne storitve in nemoteno delovanje ter razvoj skupnosti. Vsekakor pri tem mislimo na moderne, postweberjanske tipe upravljanja. Ena izmed prevladujočih modernejših paradigm upravljanja ostaja NJM, ki je kljub izrazitim kritikam najprepoznavnejši v okvirih modernejšega upravljanja.

Uvajanje načel NJM se navezuje na novo sodobno organizacijo delovnih procesov, na opredelitev in razmejitev odgovornosti ter pristojnosti, predvsem na opredelitev odgovornosti za rezultate, povečevanje avtonomije organizacije in posameznikov ter ploščenje organizacijske strukture (Žurga, 2001). Pri NJM gre tako za spojitev normativne orientacije tradicionalne javne administracije in instrumentalne 
orientacije splošnega menedžmenta. Menedžment lahko vidimo kot novo obliko vodenja poslov države na področju, ki je prej sicer "pripadalo" administriranju, vendar na drugačen način in z drugačnimi poudarki (Dunleavy \& Hood, 1994). Spremembe $v$ družbi, ki so pogojevale nastanek paradigme NJM, segajo $\vee 70$. leta prejšnjega stoletja, ko so konzervativni ekonomisti menili, da sta vlada in njena uprava ekonomski problem, ki omejuje ekonomsko rast in svobodo. Z zmanjševanjem vloge uprave in vstopom nekaterih zasebnih podjetii $\vee$ proces zagotavljanja javnih storitev naj bi dosegali tako učinkovitejše storitve kot tudi ekonomsko rast. Na osnovi ekonomskih neoklasičnih pristopov se je leta 1980 sprožil val reform, ki so nove ekonomske teorije in spoznanja poskušale vnesti v delovanje javnih uprav (Hughes, 2003). Reformiranje javnih uprav je potekalo precej neenotno in $v$ različnih oblikah. Flynn in Strehl (1996) menita, da je podlaga za razlikovanja uprav predvsem v ustavnih ureditvah, političnem mnenju na nacionalni in lokalni ravni, odnosu javnosti do uprave in zaposlenih $v$ upravi, spretnostih in znanju menedžerjev $v$ javnem sektorju, ideološkem in političnem prepričanju ter upravni kulturi. Nadalje trdita, da je $v$ državah z močno centralno vlado, zaradi nadzora nad javno upravo, implementacija reforme mnogo lažja. $V$ državah, kjer sta lokalna uprava in državna uprava bolj enakovredni in je lokalna uprava razmeroma avtonomna ter ustavno zaščitena, pa je reforma težje uresničliiva.

Širok spekter pojavnosti reforme $v$ različnih državah je odprl vrata številnim kritikom, ki so menili, da NJM ni paradigma, saj realizacija koncepta NJM ni enotna in torej ni nujno, da izhaja iz istovrstnih družbenih dražljajev. Brezovšek in Bačlija (2010) določita tri osrednje točke okoli katerih so se udejanila kritična mnenja. Prva je, da NJM predstavlja "cesarjeva nova oblačila", torej samo navdušenje in nič vsebine. Zaradi spogledovanja s širokim spektrom menedžerskih orodii iz zasebnega sektoria so razni avtorii NJM po lastni presoji dodajali nekatera orodja, ali pa druga popolnoma zanemarili. ${ }^{2} \mathrm{~V}$ tem kontekstu je NJM izgublial bitko "prepoznavnosti", sai je bil vse in nič obenem. Ni pa ponujal odgovorov na nekatere stare dileme oziroma težave upravljanja.

2 Kettl $(1995$, str. 14) na primer meni, da »NJM vključuje nasprotujoče si cilje«, Ferlieju in sodelavcem (1996, str. 10) se zdi »novi javni menedžment kot prazno platno ... nanj lahko naslikaš karkoli«. Poleg tega si paradigmo vsak avtor razlaga nekoliko drugače, kar nujno vodi $v$ nedoslednosti, kot na primer »javnim menedžerjem se omogoči več diskrecijske pravice» (Kaboolian, 1998) ter »javnim uslužbencem se omeji diskrecijska pravica» (Barberis, 1988). 
Drugi očitek je vezan na izsledke evalvacije reforme uprave, ki so $v$ mnogih državah razkrile, da NJM-ju ni uspelo zmanjšati stroškov na enoto javne storitve/dobrine (Hood, 1991). Tako reforma ni mogla izpolniti svoje glavne obljube in so njene glavne posledice "poveličevanje menedžmenta" brez otipliivih rezultatov. S pomočjo nekaterih ukrepov zmanjševanja finančnih virov javnim organizacijam so po mnenju nekaterih (Nethercote, 1989) dosegli zgolj nestabilnost v sistemu, ne pa merljivih končnih rezultatov. Tretji pogost očitek je, da NJM ne zagovarja javnega dobrega temveč je vzvod za zadovoljevanje partikularističnih interesov. NJM naj bi tako bil zgolj orodje tiste upravne elite, ki si želi uzurpirati še več moči in napredovati v sistemu javnih uslužbencev.

\subsection{NJM na lokalni ravni}

Poleg različnih manifestacii paradigme NJM v različnih nacionalnih sistemih bi bilo pričakovati, da obstajajo tudi razlike na ločnici nacionalno - lokalno. Pri tem ostaja odprto vprašanje, ali je mogoče govoriti o nekih splošnih smernicah NJM na lokalni ravni ali govorimo o prav toliko (če ne še več) manifestacijah, kolikor je lokalno samoupravnih sistemov. Vsekakor nekateri avtorii predvidevajo, da se da zakoličiti nekatere splošne smernice NJM na lokalni ravni, čeprav empirični podatki o tem praktično ne obstajajo.

Tabela 1: Delovanje lokalnih oblasti pod NJM

\begin{tabular}{|l|l|l|}
\hline & $\begin{array}{l}\text { Izvoliena lokalna oblast v času po } \\
\text { Il. svetovni vojni }\end{array}$ & $\begin{array}{l}\text { Lokalna oblast pod paradigmo } \\
\text { novega javnega menedžmenta }\end{array}$ \\
\hline $\begin{array}{l}\text { Vodilo lokalnih } \\
\text { oblasti }\end{array}$ & $\begin{array}{l}\text { Upravljanje vložkov, } \\
\text { zagotavljanje javnih storitev v } \\
\text { kontekstu države blaginje }\end{array}$ & $\begin{array}{l}\text { Upravljanje vložkov in izložkov z } \\
\text { upoštevanjem principa uspešnosti, } \\
\text { učinkovitosti in odzivnosti do } \\
\text { občanov }\end{array}$ \\
\hline $\begin{array}{l}\text { Prevladujoča } \\
\text { ideologija }\end{array}$ & $\begin{array}{l}\text { Profesionalizem in strankarska } \\
\text { pripadnost }\end{array}$ & Upravljanje in potrošništvo \\
\hline $\begin{array}{l}\text { Opredelitev javnega } \\
\text { interesa }\end{array}$ & $\begin{array}{l}\text { Politiki in strokovnjaki - občani ne } \\
\text { participirajo }\end{array}$ & $\begin{array}{l}\text { Agregat individualnih interesov, ki } \\
\text { se manifestira v uporabnikovi izbiri }\end{array}$ \\
\hline $\begin{array}{l}\text { Prevladujoči model } \\
\text { odgovornosti }\end{array}$ & $\begin{array}{l}\text { Demokracija; volitve, mandatno } \\
\text { omejeni politični funkcionarii, } \\
\text { naloge se dosežejo z izvajanjem } \\
\text { nadzora nad birokraciji }\end{array}$ & $\begin{array}{l}\text { Ločitev politike in menedžmenta; } \\
\text { politika daje usmeritve, vendar ne } \\
\text { nadzira procesa izvajanja, } \\
\text { dodatna varovalka v obliki } \\
\text { nadzora (feedback) uporabnikov } \\
\text { storitev }\end{array}$ \\
\hline $\begin{array}{l}\text { Sistem zagotavlianja } \\
\text { javnih storitev }\end{array}$ & $\begin{array}{l}\text { Hierarhična in sektorsko urejena } \\
\text { organizacija }\end{array}$ & $\begin{array}{l}\text { Zasebni sektor ali kvazi javne } \\
\text { institucije (quangos) }\end{array}$ \\
\hline
\end{tabular}

Vir: Prilagojeno po Stokerju (1996).

104 Uprava, letnik IX, 4/2011 
Poskus prikaza vpliva NJM na lokalni ravni je pripravil Stoker (1996) (glej tabelo 1). Razvidno je, da je sočasno (ali pa kot posledica NJM) decentralizacija ali dekoncentracija storitev vplivala na določeno povišano stopnjo avtonomnosti lokalno samoupravnih skupnosti, pri čemer moramo o dejanski avtonomnosti vedno kritično podvomiti. Tako je glavna usmeritev NJM na lokalni ravni namenjena prav kakovosti storitev ter ekonomičnosti. Občan je tako vedno boli uporabnik, kar pa zaradi bližine in narave lokalne skupnosti lahko vodi do zbliževanja tradicionalnih in potrošniških participativnih metod.

Vsekakor pri Stokeriu (ibidem) izstopata predvsem prevladujoča servisna funkcija lokalne ravni ter bližina prebivalcev in lokalnih oblasti, po čemer se reforma uprave na lokalni ravni razlikuje od reforme na nacionalni ravni. Vsekakor pa pri tem ne gre zanemariti že omenjene kritike, ki se lahko po enaki analogiii prevedejo tudi na NJM na lokalni ravni.

\subsection{Empirična raziskava}

Kot smo že omenili, je empiričnih (predvsem ustrezno kvalitativnih) raziskav o implementaciji NJM na splošno malo, še mani pa jih je (bilo) izvedenih na primeru lokalnih skupnosti. Redke raziskave sicer kažejo, da se je reforma javnega sektorja širše implementirala na ravni mest (Hambleton, 2004). Daeman in Schaap (2000, str. 175) na primer, sta na podlagi empirične analize na vzorcu petnajstih mest dokazala, da so orodja NJM na lokalni ravni v Evropi v splošni uporabi. Na podlagi tega podatka smo analizirali implementacijo NJM v 58 mestih $^{3} \vee$ EU, tako da smo anketirali najvišje rangirane javne uslužbence $v$ hierarhiji lokalne uprave (pri nas ta naziv ustreza nazivu direktor občinske uprave).

Kvantitativno ocenjevanje implementacije širokega nabora orodii in mehanizmov NJM je precej oteženo, zato se naslanjamo na Brudneyja,

3 Aarhus, Antwerpen, Banska Bystrica, Bialystok, Birmingham, Bonn, Bordeaux, Breda, Brescia, Brno, Brugge, Bruseli, Budimpešta, Bydgoszcz, Cagliari, Ceske Budjeovice, Debrecen, Edinburg, Eindhoven, Essen, Gent, Glasgow, Graz, Helsinki, Innsbruck, Kielce, København, Krakow, Le Havre, Leeds, Liberec, Limerick, Linz, Ljubljana, Luksemburg, Madrid, Malmö, Maribor, Modena, Nice, Oulu, Plzen, Poznan, Reggio di Calabria, Riga, Rotterdam, s\Gravenhage, Stockholm, Szeged, Talin, Tartu, Uppsala, Utrecht, Benetke, Verona, Vigo, Vilna Wroclaw. 
Heberta in Wrighta (1999, str. 22), ki so implementacijo paradigme NJM merili ${ }^{4}$ z naslednjimi kazalniki:

- izobraževalni programi (tečaji, usposabljanja, delavnice in podobno) za zaposlene $v$ upravi o izboljšanju odnosa do uporabnika ali zagotavljanja storitev,

- izobraževalni programi (tečaji, usposabljanja, delavnice in podobno) za spodbujanje timskega dela in reševanja težav pri delu,

- benchmarking za merjenje učinkov programov,

- strateško načrtovanje, ki določa jasne cilje organizacije,

- poenostavitev kadrovskih pravil,

- privatizacija večjih programov,

- ploščenje piramidne strukture organizacije.

Na podlagi teh kazalnikov smo pripravili indeks NJM. Indeks, ki je seštevek rekodiranih vrednosti odgovorov, ${ }^{5}$ je podlaga za ocenjevanje stopnje reformiranosti posamezne mestne uprave.

Nadalje smo želeli preveriti tudi, ali je implementacija NJM kakorkoli povezana z nekaterimi značilnostmi lokalne skupnosti (na primer velikost, število prebivalcev, ekonomska uspešnost ipd.). Slednje bi nam namreč dalo tudi odgovore na to, ali ima NJM kakšne dejanske merljive implikacije $v$ realnem okolju. Za ta namen smo podatke pridobljene $z$ anketiranjem združili s podatki Urban Audit'. Za izračun nekaterih drugih vrednosti (na primer BDP per capita glede na nacionalno povprečje in povprečna stopnja zaposlenosti na nacionalno povprečje) pa smo uporabili tudi baze podatkov organizacije Eurostat. ${ }^{7} \vee$ zadnji fazi raziskave

4 Brudney, Hebert in Wright (1999) so v svoji raziskavi spraševali po tem, ali so katerega od naštetih kazalnikov implementirali v zadnjih štirih letih (možni odgovori so bili na relaciii brez sprememb do popolnoma implementirane spremembe).

5 Odgovorom: nismo razmišljali o spremembah, smo razmišljali o spremembah, vendar še brez realizacije ter načrtujemo spremembe smo pripisali vrednost nič; odgovorom: delno smo spremenili in popolnoma smo spremenili smo pripisali vrednost ena. Najvišja vrednost indeksa NJM je sedem. Klasifikacija indeksa je $0-2=$ ni reforme; 3-5 = 1. faza reforme; $5-7=$ je reforma.

6 Empirične podatke, ki smo jih nato združili z empiričnimi podatki iz naše raziskave, smo pridobili iz baz podatkov organizacije Urban Audit (baze podatkov Urban Audit so dostopne na spletni strani http://www.urbanaudit.org/index.aspx).

7 Da bi omilili vpliv nacionalnih okolij na vrednosti posameznih spremenliivk, smo primerjali stanje $v$ mestu glede na nacionalno povprečje (kot odstopanje $\vee$ pozitivno ali

106 Uprava, letnik IX, 4/2011 
smo pridobliene podatke obdelali z računalniškim programom SPSS, kjer smo $v$ isti matrici združili odgovore ter spremenljivke iz baze podatkov Urban Audit.

\subsection{Rezultati}

Tabela 2: Reformiranje lokalnih uprav glede na posamezne elemente NJM

\begin{tabular}{|c|c|c|c|c|c|c|c|}
\hline & $\begin{array}{c}\text { nismo } \\
\text { razmišljali o } \\
\text { spremembah }\end{array}$ & $\begin{array}{c}\text { smo } \\
\text { razmišljali o } \\
\text { spremembah, } \\
\text { vendar še } \\
\text { brez } \\
\text { realizacije }\end{array}$ & $\begin{array}{l}\text { načrtujemo } \\
\text { spremembe }\end{array}$ & $\begin{array}{l}\text { delno smo } \\
\text { spremenili }\end{array}$ & $\begin{array}{l}\text { popolnoma } \\
\text { smo } \\
\text { spremenili }\end{array}$ & $\begin{array}{l}\text { povprečje } \\
\text { (lestvica } \\
\text { od } 1 \\
\text { do 5) }\end{array}$ & $\begin{array}{l}\text { standardni } \\
\text { odklon }\end{array}$ \\
\hline $\begin{array}{l}\text { izobraževanja } \\
\text { zaposlenih za } \\
\text { izboljšanje javnih } \\
\text { storitev }\end{array}$ & 11,5 & 1,9 & 9,6 & 40,4 & 30,8 & 3,60 & 1,524 \\
\hline $\begin{array}{l}\text { usposabljanja za } \\
\text { timsko delo in } \\
\text { timsko reševanje } \\
\text { težav }\end{array}$ & 9,6 & 9,6 & 15,4 & 34,6 & 25,0 & 3,38 & 1,497 \\
\hline $\begin{array}{l}\text { samoocenjevanje } \\
\text { s primeriavo z } \\
\text { drugimi mesti } \\
\text { (benchmarking) } \\
\text { za bolišs } \\
\text { ocenjevanje } \\
\text { naših produktov }\end{array}$ & 11,5 & 7,7 & 11,5 & 46,2 & 13,5 & 3,13 & 1,560 \\
\hline $\begin{array}{l}\text { strateško } \\
\text { načrtovanje za } \\
\text { določitev jasnih } \\
\text { ciliev }\end{array}$ & 7,7 & 5,8 & 5,8 & 42,3 & 32,7 & 3,69 & 1,476 \\
\hline $\begin{array}{l}\text { poenostavljanje } \\
\text { kadrovskih pravil }\end{array}$ & 21,2 & 5,8 & 21,2 & 36,5 & 9,6 & 2,90 & 1,485 \\
\hline $\begin{array}{l}\text { privatizacija } \\
\text { večjih javnih } \\
\text { programov }\end{array}$ & 26,9 & 15,4 & 15,4 & 25,0 & 9,6 & 2,52 & 1,540 \\
\hline $\begin{array}{l}\text { zmanjševanje } \\
\text { hierarhičnih ravni } \\
v \text { mestni upravi }\end{array}$ & 34,6 & 23,1 & 13,5 & 7,7 & 17,3 & 2,38 & 1,549 \\
\hline
\end{tabular}

Vir: Bačlija (2010) ( $N=58)$.

Po rekodiranju in kategorizaciji odgovorov smo zaključili, da 21,1 \% opazovanih lokalnih uprav ni reformiranih, $45,6 \%$ jih je $v$ prvi fazi reforme in $22,8 \%$ je reformiranih $(10,5 \%$ anketirancev ni odgovorilo na to vprašanje). Iz tabele 2 je razvidno, da je najpogostejše uvajanje

negativno smer glede na nacionalno povprečje). $V$ ta namen smo baze podatkov dopolnili z bazami podatkov organizacije Eurostat (http://epp.eurostat.ec.europa.eu/portal/ page/portal/eurostat/home/) ter tako ocenjevali uspešnost mesta glede na nacionalno okolje. S tem smo izničili ali vsaj omilili napake pri merjenju. 
strateškega načrtovanja za določitev jasnih ciljev (povprečna vrednost 3,69 ) in izobraževanje zaposlenih za izboljšanje javnih storitev (povprečna vrednost 3,60 ) najmani pogosto pa se uporabljata zmanjševanje hierarhičnih ravni $v$ lokalni upravi (povprečna vrednost 2,38 ) in privatizacija večjih javnih programov (povprečna vrednost 2,52). Ti rezultati nekoliko presenečajo, ne toliko zaradi odstotka lokalnih uprav, ki so implementirale elemente NJM, temveč zaradi elementov, ki jih najpogosteje uvajajo. Neoliberalizem, ki se je manifestiral tudi $v$ paradigmi NJM, namreč predvideva zmanjševanje vloge uprave in vstop nekaterih zasebnih podjetij v proces zagotavljanja javnih storitev (Hughes, 2003), pa vendar naša raziskava kaže, da uprave mest v EU pogosto ne uporabliajo načela privatizacije.

Naslednii korak je analiza statističnih povezav med indeksom NJM in neodvisnimi spremenljivkami. Z bivariatno analizo (glej tabelo 3) ugotovimo, da se nekatere povezave nakazujejo. Nakazuje se, da se NJM povezuje s številom prebivalcev, s povprečno stopnjo zaposlenosti, z lizbonskim benchmarkom in močjo mesta. To bi lahko pomenilo, da večje kot je mesto ter bolj kot je konkurenčno, več elementov NJM je mestna uprava implementirala. Če pa uporabimo multivariatno analizo - linearno regresijo, je jasno, da povezave niso takšne oziroma da nekatere spremenliivke prevzemajo več moči kot druge (glej tabelo 3). Interpretacija koeficientov povezanosti (beta) nam pove, da bolj kot je mesto gosto naseljeno, mani elementov NJM je implementirala lokalna uprava. To je v nasprotju z našimi pričakovanji. Sklepamo lahko, da boli kot je mesto gosto naseljeno, več dela ima na operativni ravni z ad hoc problematiko, kar očitno pušča boli malo časa za sistemske izbolišave.

Druga nakazana statistična povezava je implementacija načel NJM in povprečen BDP na prebivalca $\vee$ mestu. Iz tega bi lahko sklepali, da so bogatejša mesta nekoliko bolj naklonjena modernizaciji uprave. Zadnja nakazana povezava pa je povezava med NJM in lizbonskim benchmarkom. To je zelo zadovoljiv rezultat, saj pomeni, da sta reformiranje lokalnih uprav ter zmožnost lokalnih skupnosti, da ustvarijo visoko konkurenčno in družbeno vzdržno okolje (predvsem zaradi zaposljivosti), povezana. Lokalne uprave torej imajo določeno vlogo pri uspešnem delovanju lokalne skupnosti. 
Tabela 3: Korelacije med spremenliivkami (Pearsonov koeficient in beta koeficient)

\begin{tabular}{|c|c|}
\hline & Indeks NJM \\
\hline Število prebivalcev & $\begin{array}{l}\left.P=0,312\left(^{*}\right) \text { (sig. }=0,024\right) \\
B=0,019 \text { (sig. }=0,940)\end{array}$ \\
\hline Povprečni BDP per capita & $\begin{array}{l}P=0,317\left(^{*}\right)(\text { sig. }=0,038) \\
B=0,398 \text { (sig. }=0,150)\end{array}$ \\
\hline Indeks moči ${ }^{8}$ & $\begin{array}{l}P=0,264 \text { (sig. }=0,088) \\
B=0,159 \text { (sig. }=0,508)\end{array}$ \\
\hline Lizbonski benchmark ${ }^{9}$ & $\begin{array}{l}P=0,240 \text { (sig. }=0,147) \\
B=0,381 \text { (sig. }=0,094)\end{array}$ \\
\hline
\end{tabular}

* Povezava je značilna pri 0,05 standardne napake napovedi.

Vir: Bačlija (2010).

\section{Sklepne ugotovitve}

Nedvomno so tokovi globalizacije, decentralizacije ter neoliberalizma močno zaznamovali smer delovanja uprav lokalnih skupnosti (Judd in Parkinson, 1990; Harding, 2005; Dunford \& Kafkalas, 1992; Le Gales, 1998). Te so pod vedno večjim pritiskom zagotoviti občanom vse več storitev, ki jih nanje prelaga država. Obenem pa so zahteve občanov zaradi vpliva storitev zasebnega sektorja vedno višje. Poleg tega lokalne skupnosti tekmujejo na globalnem trgu za investitorje, kar dodatno obremenjuje lokalne uprave, saj delujejo $v$ hitro spreminjajočem se,

8 Kako močno lahko lokalne oblasti posamezne skupnosti oblikujejo oziroma vplivajo na uspešnost skupnosti, je $\vee$ veliki meri odvisno od moči lokalne oblasti. $\vee$ okviru tega je Urban Audit (na primeru mest - Indeks moči mesta) pripravil tako imenovani "indeks moči", ki je sestavljen iz več kazalnikov, kot so: avtonomnost lokalnih oblasti pri izdatkih; avtonomnost lokalnih oblasti pri obdavčevanju in delež nacionalnega BDP-ja namenjen lokalni samoupravi. Indeks poskuša ponazoriti, kako močno vlogo ima lokalna samoupravna oblast znotraj posameznega nacionalnega sistema. (Urban Audit, 2004).

9 Lizbonski benchmark je indeks za ocenjevanje realizacije Lizbonske strategije in je tesno povezan z konkurenčnostjo opazovane entitete. Sestavljen je iz naslednjih spremenljivk:

- BDP glede na celotno populacijo,

- delovna produktivnost (BDP na zaposleno osebo);

- zaposleni prebivalci (delež zaposlenih med 15 in 64 letom starosti);

- stopnja zaposlenosti starejših delavcev (delež zaposlenih med 55 in 64 letom starosti);

- dolgoročna nezaposlenost starejše populacije (delež tistih, ki so nezaposleni več, kot eno leto in so stari med 55 in 64 let);

- delež prebivalcev, ki se izobražuje višjem in visokem šolstvu (delež prebivalcev med 15 in 24 letom starosti, ki se izobražuje višjem in visokem šolstvu glede na celotno populaciio); - nezaposlenost mladih (delež mladih med 15 in 24 letom starosti, ki so nezaposleni vsaj šest mesecev). (Urban Audit, 2004). 
skorai podjetniškem okolju. Da so upravljavske naloge na lokalni ravni zahtevne, lahko ilustrativno prikažemo tudi z izsekom iz kolumne Ljubljanskega dnevnega časopisa: „Za nekatere osnovne stvari v življenju pač pričakujem, da delujejo: da se prižge luč, priteče voda iz pipe in podobno. Skratka - to, da so v Ljubljani območja, kjer ljudje že leta živijo brez kanalizacije in za odpadke skrbijo kot pred stotimi leti, me jezi. V kakšnem drugem okolju ali kakšnem drugem času me morda ne bi. «10

Da bi se lahko uspešno soočile z vsemi izzivi, je nujno, da se lokalne uprave reformirajo. Bodisi po vzoru NJM ali kakšni drugi reformistični metodi. Kljub temu da se je NJM izkazal kot (pre)širok koncept, ki se Ferlieju in sodelavcem (1996, str. 10) zdi »kot prazno platno ... nani lahko naslikaš karkoli« ter je tarča mnogih kritik, vendarle ostaja eden prepoznavnejših in najpogosteje uporabljenih podlag za reformiranje uprav. Čeprav Hambleton (2004, str. 20) meni, da je paradigma NJM nezadosten odgovor na težave, s katerimi se srečujejo lokalne skupnosti po vsem svetu, saj ponuja precej ozek pogled na javne storitve in zanemaria demokratično vitalnost institucii, se z njim ne moremo popolnoma strinjati. Menimo, da je ravno zaradi specifik lokalnega upravlianja (storitvena naravnanost, bližina uporabnika, hitra odzivnost upravnih oblasti) ta neotayloristična metoda, z vpeljevanjem racionalnih metod dela $v$ javni sektor, primerna za lokalne uprave.

Predstavljena raziskava do neke mere potrjuje naše prepričanje. $\mathrm{S}$ pomočjo načel NJM je reformiran dobršen del lokalnih skupnosti v EU. Za natančnejše podatke bi bilo potrebno izvesti več obsežnejših študii, kar bi $\checkmark$ prihodnosti usmerilo (prepotrebno) pozornost akademske in strokovne javnosti na to "podhranjeno" področje. Vsekakor kaže slediti spodbudnim rezultatom, ki kažejo na to, da se lokalne uprave "splača" reformirati. Kažejo se pozitivni učinki za celotno lokalno skupnost, za njen strateški razvoj in njeno finančno blagostanje. Dokazovanje pozitivnih učinkov upravnih reform pospešuje tudi nadalinio popularizacijo tovrstnih procesov.

10 Marjeta Bogataj, Žurnal, 14. februar, 2009.

110 Uprava, letnik IX, 4/2011 
Dr. Irena Bačlija je docentka za področje politologije na Fakulteti za družbene vede, Univerza $v$ Ljubljani in raziskovalka na Centru za proučevanje upravno-političnih procesov in institucij. Nosilka predmetov Lokalno upravljanje in Upravna kultura na drugostopenjskem študiju (Politologija - javna uprava) ter sodelujoča $v$ pedagoškem procesu pri več predmetih na dodiplomskem študiju programa Politologija - Analiza politik in javna uprava. Objavila je več monografij ter znanstvenih in strokovnih člankov $v$ domačih in tujih publikacijah. 


\section{Literatura in viri}

- (2007). Evaluation of mechanisms for the dissemination and exploitation of the results arising from programmes and initiatives managed by the Directorate-General for Education and Culture. ECOTEC. London: Priestley House.

- Bačlija, I. (2010). Urbani menedžment: koncept, dimenzije in orodja. Ljubljana: Fakulteta za družbene vede.

- Ball, G. (1967). Cosmocorporations: The Importance of Being Stateless. Atlantic Community Quarterly 6(2), 163-170.

- Barberis, P. (1988). The new public management and a new accountability. Public Administration 76(3), 451-470.

- Bramezza, I. (1996). The competitiveness of the European city and the role of urban management in improving city's performance. Hag: CIP-Data Koninklijke Bibliotheek.

- Brenner, N. \& Theodore, N. (2002). Spaces of Neoliberalism: Urban Restructuring in Western Europe and North America. Oxford, Boston: Blackwell.

- Brenner, N. (1999). Globalisation as reteritorialisation: the re-scaling of urban governance in the European Union. Urban Studies 36(3), 431-451.

- Brezovšek, M., \& Bačlija, I. (2010). Sodobna upravna misel. Ljubljana: Fakulteta za družbene vede.

- Brezovšek, M., \& Črnčec, D. (2007). Demokratična uprava in tajnost podatkov. Ljubljana: Fakulteta za družbene vede.

- Brudney, J., Hebert, T. F., \& Wright, D. S. (1999). Reinventing Government in the American states: Measuring and Explaining Administrative Reform. Public Administration Review 59(1), 19-30.

- Daemen, H., \& Schaap, L. (2000). Citizen and City: Developments in Fifteen Local Democracies in Europe. Rotterdam: Erasmus University.

- Diamond, L. (1999). Developing democracy: Toward consolidation. Baltimore: Johns Hopkins University Press.

- Dillinger, W. \& Fay, M. (1999). From Centralized to Decentralized Governance. Finance and development 36(4), 11-16.

- Dunford, M., \& Kafkalas, G. (1992). Cities and Regions in the New Europe. London: Belhaven Press.

- Dunleavy, P. \& Hood, C. (1994). From Old Public Administration to New Public Management. Public Money \& Management 14(3), 9-16. 
- Farazamand, A. (2007). Globalization and Public Administration. V: Bevir, M. (Ed.) Public governance (20-44). London: Sage.

- Ferlie, E. \& Pettigrew, A. (1996). Managing Through Networks: Some Issues and Implications for the NHS. British Journal of Management 7(1), 81-99.

- Flynn, N. \& Strehl, F. (Eds.) (1996). Public Sector Management in Europe. New Jersey: Prentice Hall.

- Fox, J. (1994). Latin America's emerging local politics. Journal of Democracy 5(2), 105-116.

- Goldsmith, M. (1998). European Integration and Local Governments. Aldershot: Edward Elgar Publishers.

- Habermas, J. (1991). The structural transformation of the public sphere: an inquiry into a category of bourgeois society. Cambridge: The MIT Press.

- Hambleton, R. (2004). Beyond New Public Management - city leadership, democratic renewal and the politics of place. City Futures International Conference. Chicago.

- Harding, A. (2005). Governance and social-economic change in cities. V: Turok, I. (Ed.) Changing Cities: Rethinking Urban Competitiveness, Cohesion and Governance (62-77). London: Routledge.

- Harvey, D. (1989). The Urban Experience. Oxford: Blackwell.

- Hood, C. (1991). A Public Management for All Seasons?. Public Administration 69(1), 3-19.

- Hughes, O. E. (2003). Public management and administration: an introduction. Hampshire: Palgrave.

- Huther, J. \& Shah, A. (1998). Applying a simple measure of good governance to the debate on fiscal decentralization. Washington, DC: World Bank.

- Judd, D. \& Parkinson, M. (1990). Leadership and Urban Regeneration. London: Sage.

- Kaboolian, L. (1998). The new public management: Challenging the boundaries of the management vs. Administration debate. Public Administration Review 58(3), 189-183.

- Keating, M. (1998). The new regionalism in Western Europe: Teritorial restructuring and political change. Cheltenham: Edward Elgar.

- Kettl, D. F. (1995). Building lasting reform: Enduring questions, missing answers. V: Kettl, D. F. \& Diluilo, J. J. (Eds.) Inside the reinvetion machine: appraising governmental reform. Washington DC: Brookings. 
- Korten, D. (1995). When Corporations Rule the World. West Hartford: Kumarian Press.

- Kroukamp, H. \& Lues, L. (2000). Improving local management. V: de Vries, M. S., Reddy, P. S. \& Haque, S. M. Improving local government: Outcomes of Comparative Research (77-92). Hampshire: Palgrave McMillan.

- Le Gales, P. (1998). Regulations and governance in European cities. International Journal of Urban and Regional Research 22(2), 482-506.

- Mayer, M. (1995). Post-fordist city politics V: Ash A. (Ed.) Post-Fordism: A reader (316-337). Oxford: Blackwell.

- Naisbitt, J. (1994). Global Paradox: The Bigger the World Economy, the More Powerful lts Smallest Players. New York: William Morrow \& Co.

- Nethercote, J. R. (1989). The rhetorical tactics of managerialism: reflections on Michaels Keating's apologia, Quo vadis?. Australian Journal of Public Administration 48(4), 363-367.

- Norquist, J. O. (1998). The Wealth of Cities Revitalizing the Center of American Life. New York: Addison Wesley Longman.

- O'Connor, J. (1973). The Fiscal Crisis of the State. New York: St. Martin's Press.

- Offe, C. (1985). Družbena moč in politična oblast: protislovja kapitalistične demokracije - razprave o politični sociologiji poznega kapitalizma. Ljubljana: Delavska enotnost.

- Pollitt, C. \& Bouckaert, G. (2004). Public management reform: a comparative analysis. Oxford, New York: Oxford University Press.

- Porter, M. E. (1998). On competition. Boston: A Harvard Business Review Book.

- Prohl, M. (Ed.) (1997). International strategies and techniques for future local government. Practical aspects towards innovation and reform. Gutersloh: Bertelsmann Foundation Publishers.

- Prud'homme, R. (1996). The dangers of decentralization. The World Bank Research Observer 10(2), 201-220.

- Rifkin, J. (1995). Konec dela: Zaton svetovne delavske sile in nastop posttržne dobe. Ljubliana: Krtina.

- Saunders, P. (1986). Social Theory and the Urban Question. London: Routledge.

- Stein, E. (1998). Fiscal decentralization and government size in Latin America. Washington DC: Inter-American Development Bank.

114 Uprava, letnik IX, 4/2011 
- Stever, J. A. (1988). The End of Public Administration. New York: Ardshley on Hudson.

- Stoker, G. (1996). Redefining Local Democracy. V: Pratchett, L. \& Wilson, D. (Eds.) Local democracy and local government (188-209). Basingstoke: MacMillan.

- Tanzi, V. (1994). Corruption, governmental activities, and markets. Washington, DC: International Monetary Fund.

- Tiebout, C. M. (1956). Apure theory of local expenditures. Journal of Political Economy 5(1), $416-424$.

- Urban Audit. (2004). Methodological Handbook: 2004 Edition. Pridobljeno 4. 12. 2008, s http://epp.eurostat.ec.europa.eu/cache/ITY_OFFPUB/KSBD-04-002/EN/KS-BD-04-002-EN.PDF.

- Vlai, S. (1992). Ustavna in zakonska ureditev lokalne samouprave. Teorija in praksa 29(1-2), 49-59.

- Weikart, L. A. (2001). The Giuliani Administration and the New Public Management in New York City. Urban Affairs Review 36(3), 359-381.

- Žurga, G. (2001). Kakovost državne uprave: pristopi in rešitve. Ljubljana: Fakulteta za družbene vede. 